ISSN: $1130-3743$

\title{
LA EDUCACIÓN MORAL ANTE LAS GUERRAS Y LOS CONFLICTOS
}

\author{
Moral education in the face of wars and struggles
}

\section{L'éducation morale face aux guerres et aux conflits}

Fernando Gil Cantero, Gonzalo Jover Olmeda y David Reyero García Universidad Complutense de Madrid. Facultad de Educación. Departamento de Teoria de la Educación. C/. Rector Royo Villanova, s/n. 28040 Madrid. Correo-e: gcantero@edu.ucm.es; gjover@edu.ucm.es y reyero@edu.ucm.es

Fecha de recepción: diciembre de 2003

Fecha de aceptación definitiva: marzo de 2004

BIBLID [(1130-3743) 15, 2003, 161-183]

RESUMEN

Este artículo presenta los resultados de una investigación de campo dirigida a conocer mejor la lectura que hacen los niños de las imágenes de otros niños que sufren las consecuencias de los conflictos bélicos y cómo imaginan que es su vida. En el texto se proponen algunas sugerencias que facilitan el objetivo de una educación para la paz, desde las construcciones narrativas de los niños. Las propuestas de educación moral para la paz suelen insistir en la idea de promover sentimientos y actitudes de solidaridad y empatía hacia los otros. Los resultados de nuestra investigación revelan la necesidad de trabajar también el conocimiento que ayude a entender las causas y extensión de los conflictos humanos.

Palabras clave: educación para la paz, educación moral, pedagogía visual. 
This paper presents the results of a fieldwork research which aim has been to get to know how Spanish children imagine other children in war, how they think their lives are. Some ideas to educate for peace in the light of children narrative construction are then suggested. The proposals of moral education for peace usually try to promote feelings and attitudes of solidarity and empathy towards others. The result of the research show that working with knowledge is also needed in order to understand the reasons of human conflicts.

Key words: education for peace, moral education, visual pedagogy.

SOMMAIRE

Cet article présente les résultats d'une recherche de terrain dont le but est de mieux faire connaître la lecture que font les enfants des images d'enfants souffrant les conséquences des conflits et de leurs représentations de ce qu'est leur vie. Le texte propose quelques idées pour une éducation à la paix, à partir des narrations des enfants. Les propositions d'éducation morale pour la paix insistent généralement sur le objectif de promouvoir des sentiments et des attitudes de solidarité et d'empathie. Les données de notre recherche révèlent la nécessité de travailler également les savoirs qui aideront à la connaissance des causes et de l'étendue des conflits humains.

Mots clef: education pour la paix, éducation morale, pédagogie visuelle.

\section{INTRODUCCIÓN}

¿Qué puede hacer la educación moral ante las guerras y los conflictos? Durante mucho tiempo, la respuesta que desde la investigación pedagógica podíamos dar a esta pregunta estaba obligada a ser más bien decepcionante. Y lo tenía que ser, simplemente, porque se consideraba que cuestiones como la educación moral y la educación en valores estaban demasiado teñidas de conservadurismo político y religioso para poder ser objeto de un trabajo de investigación y un tratamiento pedagógico adecuado. Hoy el panorama es distinto. Durante los últimos veinte años, diversos grupos de investigación en varias universidades españolas nos hemos empeñado en mostrar que cabe una investigación pedagógica rigurosa de la educación moral. No sólo que cabe, sino que no hay más remedio que acometerla si es que queremos ser fieles a lo que significa la tarea de educar. En una reunión que mantuvimos varios profesores de estos grupos a finales de 2002 en la Universidad de Valencia, acordamos que era ya momento de hacer balance de la actividad realizada en nuestras respectivas universidades, al tiempo que continuábamos 
avanzando en las líneas en marcha. Este artículo es en buena medida un resultado de aquel encuentro. En la primera parte, haremos un repaso por la evolución de este campo de investigación a lo largo de estos veinte años en el entorno académico en el que trabajamos los autores. A continuación, presentaremos un estudio de campo sobre la lectura de las imágenes del conflicto en la infancia, que hemos realizado continuando una de las líneas que desarrollamos en la actualidad. Expondremos el objetivo, estrategia metodológica y principales resultados del estudio. Para finalizar, en las conclusiones intentaremos responder a la pregunta que hemos formulado al principio, y sugerir algunas ideas para la acción educativa ante las guerras y los conflictos a la vista de los datos obtenidos en el trabajo de campo.

\section{CONTEXTO: LA INVESTIGACIÓN SOBRE EDUCACIÓN MORAL}

Como ha señalado recientemente Escámez en una excelente revisión de la investigación sobre educación en valores y educación moral desde 1975 a 2001, ésta conoció en nuestro país un importante resurgimiento a partir de la segunda mitad de los ochenta, bajo la influencia - y autoprotección - inicial del enfoque desarrollado por Kohlberg (Escámez, 2003). Concretamente, en la Universidad Complutense de Madrid, el interés por este campo de investigación, dentro del ámbito de la Teoría de la Educación, se despliega, primero tímidamente y después con mucha más fuerza, a comienzos de esos años ${ }^{1}$, promovida, sobre todo, por un grupo de profesores que empezaron su carrera académica en el antiguo Seminario de Filosofía de la Educación, integrado más tarde en el Departamento de Teoría e Historia de la Educación. Ya en un artículo publicado en 1983, José Antonio Ibáñez-Martín llamaba la atención sobre la necesidad de redescubrir este campo desde la investigación pedagógica, cuando decía:

No cabe duda que en estos momentos estamos asistiendo a un renacimiento de la educación moral. Durante muchos años se ha hablado poco, en concreto, de este tema; fundamentalmente son tres las causas: los educadores tenían un cierto temor a ofrecer una imagen pública que pudiera confundirles con predicadores religiosos; el enjuiciamiento del adelanto de los alumnos en esta dimensión se presentaba con dificultades insuperables y, además, el ambiente social se caracterizaba por una desmesurada ilusión en el adelanto de la inteligencia (Ibáñez-Martín, 1983, 17).

En el panorama internacional —añadía Ibáñez-Martín - se ve que esta situación está cambiando, "y, así, en estos últimos años, hemos visto aparecer una revista expresamente dedicada a educación moral y numerosos trabajos científicos que intentan avanzar en el estudio de esta dimensión educativa, cuya primordial

1. Esta afirmación no se opone a la propuesta de Escámez quien sitúa este resurgimiento en el año 1986, al tomar como referencia no la evidente escasez de trabajos en la primera mitad de esa década sino el influyente informe que Rassekh y Vaideanu redactaron para la Unesco (EscámEz, 2003, 211-212). 
importancia se ha descubierto con una nueva profundidad" (ibíd.). Pocos años más tarde, Sacristán insistirá en esta misma idea (Sacristán, 1988)².

Este origen ha condicionado de alguna manera el tipo de investigación realizada, en dos sentidos. En primer lugar, la educación moral no constituye un objeto o núcleo separado de investigación, sino que ésta se enmarca en el contexto de una preocupación más amplia por lo que podríamos llamar la dimensión normativo-axiológica de la educación, y, como tal, forma un conjunto con otras temáticas como, por ejemplo, la naturaleza práctica de la actividad educativa y del conocimiento pedagógico, la deontología profesional y el marco normativo del sistema educativo 3 .

Un estudio bibliométrico de las producciones generadas de 1983 a 2000 a través de las memorias de investigación del Departamento de Teoría e Historia de la Educación (Universidad Complutense de Madrid, 1995 y 2001) muestra que el tema de la educación moral y cívica ha sido objeto del $26 \%$ de nuestras publicaciones, con una evolución que a lo largo de estos años ha ido trazando una tendencia creciente.

En segundo lugar, y unido a lo anterior, la educación moral se trata dentro de lo que podríamos llamar finalidades o aspiraciones sociomorales de la educación: educación cívica, educación para los derechos humanos, educación multicultural, etc. Esto ha hecho que la investigación se haya decantado en varias líneas o áreas temáticas diferentes, que se complementan entre sí:

a) Una línea de aspectos relativos a la fundamentación de la educación moral: necesidad de la educación moral, análisis crítico de las diferentes tendencias, educación moral y socialización, requisitos de la formación del profesorado para la educación moral, educación moral e ideología, adoctrinamiento y educación moral, la educación moral en una sociedad pluralista, etc. ( $24 \%$ de la producción en este campo).

b) Una segunda línea en torno a la educación cívica: relaciones entre la educación moral y la educación cívica, requisitos de la educación cívica en una sociedad democrática, el debate liberal-comunitarista, competencias de la educación para la ciudadanía, la educación cívica en el currículo, programas internacionales de educación cívica, educación cívica e identidad colectiva, la educación cívica en la infancia, etc. (27\% de la producción).

c) Una tercera línea sobre educación para los derechos humanos: el sentido pedagógico de los derechos humanos, la experiencia infantil de los

2. Lamentablemente, la muerte prematura de David Sacristán no le permitió continuar lo que ya entonces se adivinaba como una fructífera línea de trabajo.

3. Es lógico que para iniciar los pasos de investigación en un ámbito se recurra a los conocimientos más asentados en el mismo. Así, en otras universidades, el primer interés por la educación moral, la educación en valores, etc., se integra en marcos referidos a la visión tecnológica y científica de las teorías de la educación (EsCÁmez, 1983), en marcos sistémicos (Puig Rovira, 1986), etc. 
derechos, la enseñanza de los derechos humanos en los diferentes niveles educativos, etc. (20\% de la producción).

Estas tres áreas comprenden conjuntamente el $71 \%$ de la producción bibliográfica en el entorno de la educación moral. El 29\% restante se lo reparten una línea sobre teoría de los valores aplicada a la educación (12\%), otra sobre educación para la tolerancia, solidaridad y paz (que incluye también estudios de fundamentación, junto a otros más aplicados) (10\%) y una tercera línea emergente a lo largo de los noventa sobre educación intercultural (7\%).

Estas líneas no han tenido todas el mismo peso a lo largo de estos veinte años. En realidad ha habido una evolución bastante clara donde la investigación sobre fundamentación de la educación moral ha ido dejando cada vez más lugar a una orientación más aplicada. Esta evolución es explicable, toda vez que ya no existen las discusiones de décadas atrás sobre lo que es y no es educación moral, bien porque se haya logrado un mayor acuerdo, bien porque el propio contexto de postmodernismo epistemológico haya hecho mucho más incómoda esta pregunta ${ }^{4}$.

\section{GRÁFICO 1}

EVOLUCIÓN DE LA PRODUCCIÓN EN LAS LÍNEAS DE INVESTIGACIÓN SOBRE EDUCACIÓN MORAL

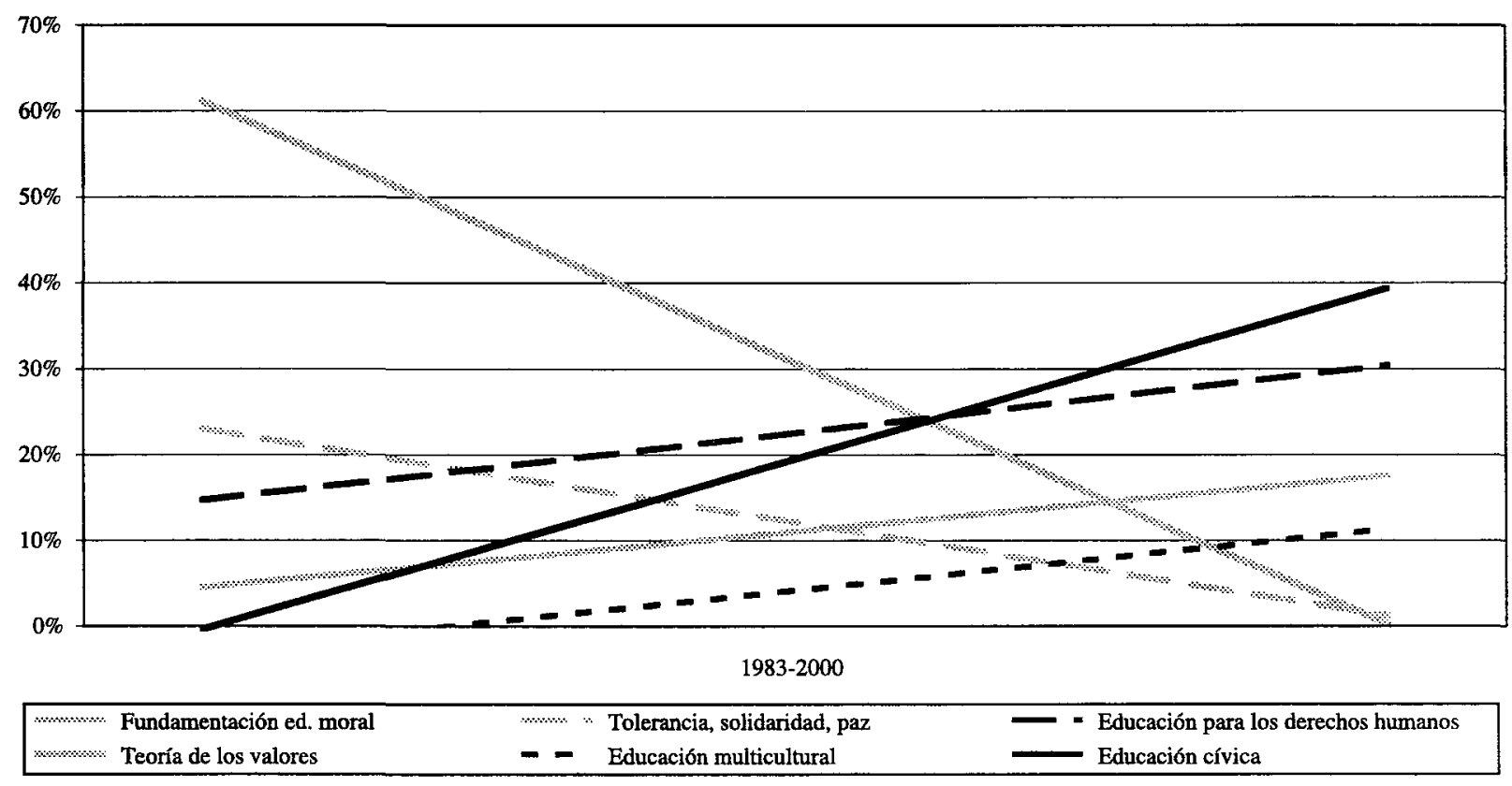

4. Tal vez, no sea absurdo considerar que el paulatino cambio de enfoques teóricos a más aplicados, se haya acompañado además de un cambio en los mismos temas, pues no cabe duda que la esfera de lo cívico, de los comportamientos públicos y colectivos, puede y debe ser objeto de enfoques educativos más precisos, concretos y pragmáticos (GIL y JovER, 2003). 
Una evolución parecida puede detectarse en los grupos de investigación de otras universidades españolas, según ha observado, con alcance general, Escámez, quien en el trabajo citado anteriormente señala que "en definitiva, la etapa última de estos años se caracteriza por el inicio de un cambio en los intereses de los investigadores: la investigación en valores se empieza a hacer desde la perspectiva de la ciudadanía y desde un sincretismo teórico" (Escámez, 2003, 228).

Para ilustrar este cambio hemos realizado un análisis de las referencias de una muestra de treinta artículos publicados por los autores españoles que trabajan en el campo de la educación moral en diferentes revistas, desde mediados de los ochenta hasta los inicios de la década actual. Tomamos como punto de partida el año 1986, fecha en la que Escámez sitúa el resurgimiento del interés por este tema en nuestro país (ibíd., 211), y que se corresponde, por otra parte, con la publicación del primer número de la revista Teoría de la Educación, que se hace eco de este interés (Ortega, 1986). Esto ha dado lugar a unas 920 referencias en las que hemos basado este análisis ${ }^{5}$. Se han distinguido cuatro grupos de investigación: el formado por profesores de la Universidad de Barcelona (GREM); el formado por profesores de las Universidades de Valencia y Murcia (que hemos considerado como un grupo unitario por razones de origen); el de profesores de la Universidad Complutense; y un último grupo, que no es estrictamente un grupo constituido, que incluye aportaciones diversas de profesores de otras universidades. Para calcular el impacto que han tenido los diferentes autores, se han tenido en cuenta dos criterios. En primer lugar, lo que hemos llamado "el rango", esto es, el número de grupos de investigación diferentes que citan a unos autores o a otros. En segundo lugar, la frecuencia, o número de profesores diferentes que lo citan. Cruzando ambos criterios, se obtiene el siguiente resultado sobre los diez autores extranjeros más citados. En estos resultados se observa el predominio del enfoque cognitivo y, en general, del legado ético kantiano.

5. Las revistas consultadas han sido las siguientes: Teoría de la Educación. Revista Interuniversitaria, Revista Española de Pedagogía, Revista de Educación (MECD), Revista Interuniversitaria de Formación del Profesorado, Pedagogía Social. Revista Interuniversitaria, PAD'E, Perspectiva Escolar, Revista Iberoamericana de Educación, y Encounters on Education. 
FERNANDO GIL CANTERO, GONZALO JOVER OLMEDA Y DAVID REYERO GARCÍA

TABLA 1

IMPACTO DE AUTORES

\begin{tabular}{|l|c|c|c|c|c|c|}
\hline Autor & Frecuencia & Rango & Val./Murc. & Barcelona & Complut. & Otros \\
\hline KOHLBERG & 10 & 4 & $\mathrm{X}$ & $\mathrm{X}$ & $\mathrm{X}$ & $\mathrm{X}$ \\
\hline PETERS & 5 & 4 & $\mathrm{X}$ & $\mathrm{X}$ & $\mathrm{X}$ & $\mathrm{X}$ \\
\hline RAWLS & 5 & 4 & $\mathrm{X}$ & $\mathrm{X}$ & $\mathrm{X}$ & $\mathrm{X}$ \\
\hline TAYLOR & 5 & 3 & & $\mathrm{X}$ & $\mathrm{X}$ & $\mathrm{X}$ \\
\hline PIAGET & 5 & 2 & $\mathrm{X}$ & $\mathrm{X}$ & & \\
\hline CAMILLERI & 4 & 3 & $\mathrm{X}$ & $\mathrm{X}$ & & $\mathrm{X}$ \\
\hline HABERMAS & 4 & 3 & $\mathrm{X}$ & $\mathrm{X}$ & $\mathrm{X}$ & \\
\hline MACINTYRE & 4 & 3 & $\mathrm{X}$ & & $\mathrm{X}$ & $\mathrm{X}$ \\
\hline BANKS & 3 & 3 & $\mathrm{X}$ & & $\mathrm{X}$ & $\mathrm{X}$ \\
\hline GADAMER & 3 & 3 & & $\mathrm{X}$ & $\mathrm{X}$ & $\mathrm{X}$ \\
\hline
\end{tabular}

Para matizar un poco más, hemos realizado un desglose de estos resultados en dos periodos diferentes: de 1986 a 1995 y de 1996 a 2001. Se ha empleado el año 1995 como separación porque hacia la mitad de la década de los noventa se publican algunos trabajos en los que se cuestiona la pretendida neutralidad del formalismo ético ${ }^{6}$.

Las tablas siguientes muestran los resultados para cada uno de estos dos periodos. En el primero (tabla 2), se sigue detectando el predominio del enfoque cognitivo y de la discusión en torno al mismo ${ }^{7}$.

TABLA 2

IMPACTO DE AUTORES (1986-1995)

\begin{tabular}{|l|c|c|c|c|c|c|}
\hline Autor & Frecuencia & Rango & Val./Murc. & Barcelona & Complut. & Otros \\
\hline KOHLBERG & 7 & 4 & $\mathrm{X}$ & $\mathrm{X}$ & $\mathrm{X}$ & $\mathrm{X}$ \\
\hline PETERS & 6 & 4 & $\mathrm{X}$ & $\mathrm{X}$ & $\mathrm{X}$ & $\mathrm{X}$ \\
\hline PIAGET & 4 & 2 & $\mathrm{X}$ & $\mathrm{X}$ & & \\
\hline BERKOWITZ & 3 & 2 & $\mathrm{X}$ & $\mathrm{X}$ & & \\
\hline POWER & 3 & 2 & $\mathrm{X}$ & $\mathrm{X}$ & & \\
\hline
\end{tabular}

6. Así, por ejemplo, Martín (1994) y BÁrCENA, Gil y Jover (1995).

7. A partir de estos cinco primeros nombres, se produce una gran dispersión en los autores citados, contabilizando trece que obtienen dos puntos de frecuencia y de rango. 
En el periodo posterior (tabla 3), esta discusión queda en un segundo plano: el peso de Kohlberg se reduce, desaparecen Peters, Berkowitz, etc., y entran nuevos autores, sobre todo en relación con la educación en contextos de pluralismo cultural.

TABLA 3

IMPACTO DE AUTORES (1996-2001)

\begin{tabular}{|l|c|c|c|c|c|c|}
\hline Autor & Frecuencia & Rango & Val./Murc. & Barcelona & Complut. & Otros \\
\hline TAYLOR & 5 & 3 & & $\mathrm{X}$ & $\mathrm{X}$ & $\mathrm{X}$ \\
\hline CAMILLERI & 4 & 3 & $\mathrm{X}$ & $\mathrm{X}$ & & $\mathrm{X}$ \\
\hline RAWLS & 4 & 3 & $\mathrm{X}$ & & $\mathrm{X}$ & $\mathrm{X}$ \\
\hline BANKS & 3 & 3 & $\mathrm{X}$ & & $\mathrm{X}$ & $\mathrm{X}$ \\
\hline HABERMAS & 3 & 3 & $\mathrm{X}$ & $\mathrm{X}$ & $\mathrm{X}$ & \\
\hline KOHLBERG & 3 & 3 & $\mathrm{X}$ & $\mathrm{X}$ & & $\mathrm{X}$ \\
\hline KYMLICKA & 3 & 2 & & $\mathrm{X}$ & $\mathrm{X}$ & \\
\hline
\end{tabular}

Volviendo otra vez al ámbito de la Universidad Complutense, en la actualidad podemos destacar tres tendencias generales. Por un lado, algunos profesores mantienen su principal línea de trabajo en torno al esclarecimiento antropológico-filosófico de los valores, en unos casos, con consideraciones educativas ${ }^{8} \mathrm{y}$, en otros, con cierto énfasis en su fundamentación filosófica ${ }^{9}$. La segunda tendencia, se centra en el análisis de la educación moral y cívica desde una perspectiva de la formación humana como acontecimiento experiencial ${ }^{10}$. Por último, desde 1997 , los firmantes de este artículo venimos trabajando en una línea de investigación sobre pedagogía infantil, dirigida a esclarecer, mediante metodologías innovadoras, aspectos relacionados con la educación moral, la educación cívica, la imagen que los niños tienen de otros niños, los derechos humanos, etc. Nuestro propósito se centra en desarrollar métodos de investigación aplicada que nos permitan, al mismo tiempo, ampliar los conocimientos descriptivos sobre el desarrollo moral de la infancia y mejorar los procedimientos de enseñanza y de educación en general. Nos interesa,

8. Hay que destacar aquí la amplia producción bibliográfica que con esta orientación viene realizando IBÁñEZ-MARTín (entre las últimas referencias, 2000 y 2002). Este interés le ha llevado, por otra parte, a la organización del curso de postgrado sobre Educación moral y educación cívica que desde el año 2002-2003 se imparte, con notable éxito, en la Facultad de Educación de la Universidad Complutense.

9. En esta línea, hay que situar las aportaciones de BARRIo MAESTRE (como publicaciones más recientes, 2002 y 2003 ).

10. Fernando Bárcena está reconocido como uno de los principales especialistas españoles en esta línea de trabajo, que inició en los noventa con las investigaciones sobre educación y ciudadanía desde el debate liberal-comunitarista (BÁRCENA, 1997) y ha seguido posteriormente con una orientación más experiencial (BÁRCENA, 2001). 
en este sentido, recurrir a nuevas estrategias de investigación, escasamente utilizadas en nuestro ámbito, como la antropología visual, las técnicas narrativas y autorreferenciales o autobiográficas, y la investigación a través de Internet. Cada una de estas técnicas ha sido previamente investigada en sus fundamentos teóricos, metodológicos y posibilidades pedagógicas de aplicación ${ }^{11}$.

\section{INVESTIGANDO LA PERCEPCIÓN DE LOS CONFLICTOS EN LA INFANCIA: LA VIDA TRAS LAS IMÁGENES}

\subsection{Objetivo de la investigación}

El estudio que presentamos a continuación sigue la última línea de investigación a la que nos referíamos al final del apartado anterior. En este caso, toma ocasión concreta de la declaración por la Asamblea General de las Naciones Unidas del primer decenio del siglo XxI como Decenio Internacional de una cultura de paz y no violencia para los niños del mundo. El informe elaborado por el organismo internacional con este motivo, destaca una vez más el papel que en la construcción de una cultura de paz tienen tanto los sistemas formales de educación como los cauces informales, y subraya la necesidad de enseñar y aprender a leer los mensajes e imágenes que transmiten los medios de comunicación (Asamblea General de las Naciones Unidas, 2000). Asumiendo tal necesidad, la finalidad de esta investigación de campo ha sido poner a disposición de las escuelas una actividad que nos ayudase a conocer mejor la lectura que hacen los niños de las imágenes de otros niños que sufren las consecuencias de los conflictos bélicos, y cómo imaginan que es su vida.

En una revisión del tema, realizada a mediados de los noventa en el marco de los estudios de Educación Comparada de la Oficina Internacional de Educación, notaba la autora noruega Birgit Brock-Utne las dificultades para llevar a cabo un programa de educación para la paz. Dificultades, primero, en lo que se refiere a la determinación del contenido de estos programas, el cual toca cuestiones que son objeto de valoraciones distintas desde diferentes opciones políticas. Elegir un contenido u otro, un enfoque u otro, no es una decisión neutral ${ }^{12}$. Dificultades, des-

11. Esta línea de investigación ha dado lugar hasta ahora a varios informes de investigación y diversas publicaciones: Gil y JOVER, 1998, 2000 y 2003; GIL, JOVER y REYERO, 2001; JOVER y REYERO, 2000. Una de estas investigaciones recibió el Premio Infancia de la Comunidad de Madrid en el año 2000.

12. En nuestro entorno cercano, Ortega y Mínguez comparten con esta autora la idea de que ala educación para la paz es educación en y para los derechos humanos (ORTEGa y Mínglez, 2001, 238). También nosotros compartimos esta apreciación, y por este motivo la actividad escolar que sustenta el diseño metodológico de la investigación, ha estado basada en el marco de fundamentación pedagógica y esquema didáctico para el desarrollo de actividades de educación para los derechos humanos que propusimos en nuestro libro La enseñanza de los derechos bumanos. 30 preguntas, 29 respuestas y 76 actividades (GIL, JOVER y REYERO, 2001). 
pués, para convertir este conocimiento en actitudes, pues sin duda ambos planos del trabajo pedagógico son necesarios; el conocimiento es requisito para el cambio de actitudes, pero el conocimiento por sí sólo no produce este cambio (BrockUtne, 1994). Lo que encontramos aquí es, ni más ni menos, que una reedición moderna de la vieja pregunta que Platón puso en boca de Menón: «Puedes decirme, Sócrates, si la virtud puede ser enseñada? ¿O no puede ser enseñada sino adquirida por ejercicio? ¿O ni puede adquirirse por ejercicio, ni aprenderse, sino que por naturaleza, o de algún otro modo, sobreviene a los hombres?" (Menón, 70a).

Nuestra investigación pretende ofrecer algún dato empírico a esta discusión. Hemos querido averiguar cómo se imaginan los niños el sufrimiento de otros niños en situaciones bélicas, para, a partir de sus construcciones, proponer algunas sugerencias que faciliten el objetivo de una educación para la paz.

\subsection{Metodología}

La investigación se llevó a cabo a través de un recurso que situamos en Internet y difundimos a través de los programas de nuevas tecnologías y redes telemáticas de diferentes administraciones educativas españolas ${ }^{13}$. En el estudio de campo participaron 360 niños, entre 8 a 12 años, de cinco colegios de Educación Primaria situados en distintos pueblos y ciudades de las comunidades de Castilla y León, Castilla La Mancha y Madrid.

Como instrumento de investigación utilizamos fotografías de niños en distintas situaciones de guerra. Pensamos que la utilización de imágenes como método para provocar las respuestas de los niños es muy pertinente. Resulta indudable que en el mundo actual los medios audiovisuales son importantísimos instrumentos a la hora de crear cultura, o de manera más precisa, a la hora de determinar esquemas que ayuden a la creación de formas concretas de representación. La utilización de determinadas imágenes y de algunos temas, como el interculturalismo o la paz, en favor de intereses comerciales puede ser una forma de buscar algún tipo de legitimación social (Giroux, 1994). En cualquier caso, la imagen es un instrumento crucial cuando los niños tratan de formarse una idea acerca de lo que es el mundo y de lo que les pasa a otros niños menos afortunados. En nuestra sociedad, los niños aprenden a situarse en el mundo a través de las imágenes estereotipadas que ven en la televisión, por eso resulta fundamental entender cómo funcionan éstas en sus mentes, cómo se entrecruzan con discursos orales para reafirmarlos o negarlos ${ }^{14}$.

En nuestra investigación, queríamos conocer cómo transforman los niños la visión de esas imágenes, sin mediar explicación alguna por parte de un adulto, en

13. Dirección: www.ucm.es/info/quiron/edupaz.html.

14. El uso de este tipo de instrumentos ha sido por ello recurrente en varias de nuestras últimas investigaciones sobre pedagogía infantil. Un estudio más detallado de sus posibilidades puede encontrarse en JOVER Y REYERO (2000). 
ideas sobre el sufrimiento y la guerra. Por ello, la única instrucción que se les daba es que imaginasen y relatasen cómo es la vida de los niños que veían en ellas.

Las fotografías mostradas se seleccionaron atendiendo a los siguientes criterios: a) que representasen situaciones bélicas o de sufrimiento; b) que apareciesen niños como protagonistas centrales; c) que representasen tanto a niños como a niñas y d) que fuesen similares a las que habitualmente se pueden contemplar en los diferentes medios de comunicación. A partir de estos criterios, elegimos dos fotografías $^{15}$. La primera mostraba a dos niñas de pie, apoyadas sobre una pared de sacos de arena, con la mirada fijada en la cámara. La niña más alta porta una metralleta; a su lado, otra niña más pequeña, y cerca de ésta un bazooka de más altura que ella, apoyado en la pared de sacos. Ambas llevan un hiyab o velo en la cabeza, que es por lo único que en realidad podemos definir su género. Detrás de ellas sólo se ve, a lo lejos, una puerta, a la que se accede a través de dos escalones, y la parte baja de una ventana. La segunda fotografía representaba a un grupo de cuatro niños y niñas sentados o en cuclillas, bajo una cavidad estrecha formada por unos listones de madera. Cerca del grupo hay un puchero muy grande. Uno de los niños agarra un trozo de pan. Están muy juntos y con ropa de abrigo.

Para el desarrollo de la actividad escolar, la clase se dividía en dos grupos, cada uno de los cuales trabajaba una de las dos fotografias. Para facilitar la tarea de recogida de datos, se diseñaron unas hojas o plantillas de trabajo para los niños con las fotografías correspondientes, acompañadas del siguiente texto: "Ésta es la imagen de unas niñas (en la primera), o unos niños (en la segunda), de un país en guerra. Cuéntame cómo es su vida: ¿Qué hacen? ¿Qué tal lo están pasando? ¿Qué le sucede a su familia? ¿A sus amigos?... Y todo lo que tú imagines sobre las vidas de esas niñas (o niños)". Estas plantillas, accesibles a través del recurso situado en Internet, permitían tanto el trabajo en línea como la descarga y trabajo en papel. En cada plantilla, los alumnos participantes tenían que rellenar el nombre del colegio, su nombre y edad, y escribir un relato sobre la vida de los niños/niñas que veían en la fotografía. Estos relatos han constituido el material para nuestra actividad interpretativa.

\subsection{Resultados: análisis e interpretación}

En este tipo de investigaciones, los resultados y análisis pueden presentarse en diferentes formatos, en función de si lo que se quiere acentuar son los textos de los niños, los temas o categorías, las interpretaciones de los investigadores, etc. Los autores de este estudio hemos optado por un sistema mixto en el que, respetando las ideas de los niños tal y como las expresaron, las utilizamos para ejemplificar nuestras interpretaciones, ordenadas en diversas categorias. Las categorías se han identificado a partir de la relevancia que los niños dan en sus relatos a

15. Fotografías adaptadas de la iniciativa La voz de los jóvenes, promovida por Unicef (www.unicef.org/voy). 
ciertos temas. De este modo, los temas que presentaremos a continuación son los que los propios niños han ido manifestando cuando se imaginan a otros niños en esas situaciones de conflicto, apareciendo así, como no podía ser de otro modo, la comparación de la vida cotidiana de los autores de los relatos con la de los niños de las fotografías. Tras el análisis e interpretación, presentaremos unas conclusiones acerca del interés pedagógico de este tipo de investigaciones, así como algunas sugerencias para mejorar la acción educativa con respecto a los medios de comunicación y la educación para la paz ${ }^{16}$.

\subsubsection{Las percepciones de la guerra y las vías de la paz}

En la guerra nadie gana, todo el mundo pierde (Pablo, 11 años).

Los niños consideran que las guerras no tienen ningún sentido, ninguna utilidad. No encuentran razón alguna que justifique una guerra. Para ellos, las desgracias que ésta trae consigo son tan numerosas que en ningún caso piensan en la necesidad de comenzar un conflicto bélico para lograr algo valioso. Para los niños las guerras se inician, en realidad, por "tonterías", no por algo importante. Belén de 11 años lo expresa diciendo: “Se hacen guerras porque este trozo de tierra es mío, que no, que es mío... y surge por una tontería. Piensan que, en muchos casos, las empieza "algún loco", "un monstruo", por "venganza" o "porque le apetece matar". En ocasiones, sobre todo los niños más mayores de la investigación, consideran que las guerras se originan "por la culpa de factores culturales, religiosos o políticos" (Rosario, 12 años). Para otros, responden a la propia maldad de los hombres. Alberto, de 12 años, estima que "la guerra demuestra la crueldad del hombre en estado puro". Los niños tienden también a considerar que las guerras se inician por una cadena de acontecimientos de acción y respuesta. "Uno mata a alguien conocido o familiar, y entonces ese al que le han matado a un conocido o pariente le mata otro conocido o familiar del otro y luego el otro, luego el otro y así sucesivamente" (Rafael, 12 años).

En sus relatos se observa que desprecian la labor de los políticos, a los que suelen hacer responsables de que se produzcan estos conflictos, porque piensan que si tuviesen que estar como los niños de las fotografías, con toda seguridad, tratarían de poner todos los medios para evitarlos. "Los niños y los ciudadanos son los únicos que sufren y no los políticos que son los que ordenan matar y los que deberían estar allí donde están esos niños" (María, 12 años). Separan con total claridad a los que mandan y no "guerrean", de los que obedecen y tienen que luchar aunque no quieran, y entienden que quienes empiezan una guerra lo hacen

16. Conforme a las normas deontológicas de la investigación educativa, en los relatos y comentarios que siguen respetamos el anonimato de los niños participantes, cuyos nombres han sido cambiados. Se ha mantenido la edad original. 
porque nunca padecen ni sufren las consecuencias terribles de la misma, ni en ellos mismos ni en sus hijos o hijas. Para los niños la guerra es algo tan malo, que si alguien la apoya es porque no la entiende, no está allí, o es un loco. Por eso Carolina, de 12 años, propone que "antes de empezar una guerra haceros esta pregunta: ¿Tienen los niños la culpa de los conflictos ajenos? Y pensar que los niños tienen los mismos derechos que un adulto o más".

La guerra es vista como una actividad principalmente masculina (contradiciendo lo que parece expresar al menos una de las fotografias mostradas). "Hay niños que sólo tienen madre porque su padre está en la guerra" (Judith, 10 años). "Los niños empiezan desde los seis años aproximadamente las guerras, mientras que las niñas se quedan en casa ayudando a su madre a cuidar de sus hermanos pequeños" (Esther, 10 años).

Los niños piensan que la paz se puede lograr básicamente dialogando. Para ellos es necesario "discutir civilizadamente", encontrar soluciones que en ningún caso supongan matar. Antonia, de 11 años, se sorprende de que los adultos no hablen: "Las cosas se pueden solucionar hablando que para ello nos dieron la voz y no matando ¿o si perdiendo vidas humanas se arreglan las cosas?". En sus construcciones narrativas, la capacidad de hablar, de dialogar o de discutir tiene que llegar, además, a la voluntad de lograr acuerdos entre las partes afectadas: "Que se pongan de acuerdo para hacer lo que prefieran los dos" (Luis, 9 años). Para los niños, la carencia de diálogo se debe a que a esos adultos que "guerrean" no se les ha enseñado "la importancia de la paz, el amor, la solidaridad y la amabilidad" (Patricia, 10 años).

Otra de las vías que proponen para evitar estos conflictos, como veíamos antes, consiste en conseguir que quienes deciden las guerras sufran en su propia piel las consecuencias. Piensan que si alguien quiere la guerra es porque no conoce ni imagina lo que se puede llegar a sufrir. Por eso para Irune, de 11 años, la solución a las guerras consiste en que "hay que ponerse en el lugar de estas niñas, imaginar que esto nos esté pasando a nosotros, a usted. ¿A que le gustaría que le ayudasen, que le dieran una familia, un hogar, algo que le pudiese ayudar?".

Pero la guerra puede percibirse también como un acontecimiento tan normal que resulte difícil encontrar una posible solución. "Los niños de la foto están en guerra, serán de unos 7 u 8 años, esa edad a nosotros no nos parece muy adulta como para estar en guerra, sin embargo, eso es muy normal para ellos" (Eva, 10 años). "Será muy difícil parar esas guerras ya que todos los que participan se han hecho a la idea de esas guerras" (Nuria, 11 años). "(Los niños) sólo pueden esconderse y esperar a que todo esté tranquilo, pero nunca se acaba, nunca sucede nada nuevo, siempre en guerra es como si fuese una tradición" (Alfonso, 10 años).

En los relatos infantiles se detecta que dan más valor a la vida de las personas que a la solución del conflicto. La paz consiste más en lograr el bienestar de las personas que acabar con los motivos de la guerra. Para los niños, este bienestar, especialmente cuando ven otros como ellos, es un criterio de actuación tan urgente que no puede esperarse a "lograr la paz" sino que hay que "ir a por la gente que 
está en guerra" (Asma, 10 años), "ayudarles a emigrar"... No comprenden que no se haga algo de inmediato, les sorprende que situaciones como las que revelan las fotografías estén pasando en este mismo momento y que no se considere prioritaria su solución. Laura, 12 años, lo expresa así:

Yo les ayudaría, pero hay que darse cuenta de que ahí para ayudar hay que arriesgar, es eso, es la muerte y yo me pregunto ipor qué no le dan más importancia a estas situaciones que son de suma importancia?

La preeminencia de la vida frente a la paz les lleva también a proponer "guerras virtuales" en las que se mantiene el enfrentamiento pero sin muertes. Gabriela, de 12 años, dice:

A mí se me ha ocurrido una idea y a lo mejor parece una tontería pero nadie moriría ni saldría malherido; se trata de que en vez de luchar por medio de armas, que luchen por medio de videojuegos, así los niños no sufrirían ni padecerían hambre. Ya sé que al principio sería un poco difícil pero en vez de entrenar soldados para luchar que los entrenen para jugar.

Por último, es importante destacar que las situaciones de sufrimiento que generan las guerras despiertan en los niños una actitud de compasión y de solidaridad que resultará indispensable para poder realizar una auténtica educación para la paz.

Si a mí me dieran la opción de parar la guerra, la aceptaría y abriría una asociación, para que la gente enviara a las familias inocentes dinero para poder vivir como se merecen (Esther, 10 años).

Si estuviera con algún niño en este momento intentaría cuidarlo lo mejor posible porque han sufrido mucho, y a mí eso me afecta bastante (Elisa, 11 años).

\subsubsection{La vida tras las imágenes}

Su vida ha dejado de ser como la vida de cualquier niño, como la mía (Mercedes, 10 años).

Los niños son capaces de ponerse en el lugar de las víctimas de la guerra, especialmente cuando son otros niños. Según Víctor, de 10 años, «la guerra es algo que perjudica a todos, sobre todo a los niños porque tienen las defensas más débiles". En los relatos que han elaborado, muestran una mayor empatía con las necesidades de sus iguales, saben ponerse en su lugar, imaginar su sufrimiento y determinar con claridad lo que les falta, lo que como niños no pueden hacer. En el fondo, captan la vida que se esconde tras unas imágenes, desgraciadamente demasiado habituales.

En las concepciones que se forman de otros niños en situaciones bélicas, su vida está llena de miedo, pobreza y tristeza. La guerra se asocia con el temor permanente a la muerte, que no hace distinciones, "porque los soldados no les ven 
como niños, sino como futuros guerreros o enemigos" (Gonzalo, 12 años). La amenaza y la incertidumbre llena la totalidad del tiempo y expulsa de él todo lo que no sea sufrimiento y temor. Es una situación de alerta permanente, donde no hay lugar para el descanso.

Lo peor de vivir en ese país, es que no puede dormir, ni pensar en nada más que no sea la guerra, no sabe si al día siguiente va a ser su turno y si va a morir, o si dentro de ocho minutos será huérfana. Nadie lo sabe, a veces no lo sabe ni el enemigo (Nuria, 11 años).

Apenas duermen, porque además de no tener cama, la noche no existe para ellos (Eva, 10 años).

Los niños son los que más sufren porque "no pueden defenderse como un adulto" (Carolina, 12 años). Muchas veces, intentan justificar algunas de las situaciones que sugieren las fotografías mostradas, imaginando que si los niños van a la guerra o usan arman, es porque los adultos les están obligando: "Un mayor -explica Teresa de 10 años- puede coger a un niño de cinco o diez años como nosotros y le da una metralleta y le dice "como no dispares te mato". Los niños tenemos que ser libres". Para Julio, de 10 años, "los que peor lo pasan son los niños porque les dan un fusil y les echan a matar como si fueran animales". A veces, el uso de las armas se justifica como defensa propia o de los cercanos: "A mí me parece que lo que están haciendo está mal y está bien porque a lo mejor están matando a gente pero también se están defendiendo" (Luisa, 9 años). Otras consideran que la participación de los niños en la guerra se debe a que han sido ueducados desde que nacen en el odio, son enseñados a matar y no a jugar o a aprender" (Irune, 11 años).

Los sujetos de nuestra investigación han volcado en la vida de los niños que sufren la guerra las representaciones más negativas que tienen de la existencia. "No saben ni sumar ni restar, y tampoco saben hablar. Ellos son pobres y no van peinados" (Susana, 11 años). Sus casas han sido destruidas y no tienen ni comida ni agua. "Se alimentan de bazofia" (Antonio, 11 años), de los desperdicios que cogen de la basura y de la ayuda que reciben de otros países, de las organizaciones internacionales, o "del SERCAM" ${ }^{17}$ (Miguel, 11 años). "Tampoco tendrán ropa para vestirse. Sólo van con trapos sucios y rotos que se encuentran en el suelo" (Yolanda, 11 años). "Van descalzos" (Diego, 11 años) y "probablemente les contagien el SIDA" (Elena, 11 años).

La vida allí es horrible: no comen casi, apenas beben y viven muy mal. Su vivienda es una pequeña casa o no tienen por la guerra que puede durar mucho tiempo. Cuando acaba, no hay material para volverla a hacer. La mayoría viven solos porque la guerra coge a su familia para luchar. La mayoría de sus amigos mueren o por la guerra o por la pérdida de comida y bebida. Siempre están yendo de un lado

17. Servicio de Emergencia y Rescate de la Comunidad de Madrid. 
para otro para huir de las guerras o para coger comida. Viven a base de los helicópteros de los países ricos para darles comida (Manuel, 11 años).

La guerra sustrae a los niños su infancia. "Su vida, su desarrollo y su educación se han roto" (Juan, 11 años). "Las escuelas se quedan vacías por temor a las bombas" (Darío, 11 años), o "se convierten en cuarteles" (Lucía, 10 años). "Estos niños, dice Nuria (11 años) sueñan en el colegio al que nosotros muchas veces no queremos ir y el que tantos disgustos nos ha dado". "Seguramente no saben leer, pero sí saben utilizar una metralleta" (Mónica, 11 años). Tampoco hay lugar para el juego, permanentemente ocupados como están en protegerse o combatir. "Jugar no deben saber lo que es" (Beatriz, 11 años). "Los parques son ahora cementerios" (Lucía, 10 años) y "los juguetes se cambian por armas de fuego" (Nicolás, 10 años). "Me imagino que sus vidas serán duras y tristes sin ningún juguete o amigo con el que jugar, ellas tendrán mucha imaginación" (Silvia, 11 años).

Las numerosas tragedias que los niños ven en las guerras, adquieren una singular expresión en las familias: "Es horroroso, montones de personas se quedan sin viviendas, sin padres, sin hermanos, sin felicidad y todo esto por unos monstruos que no saben dialogar" (Rosario, 10 años). Suelen imaginar que los niños y las niñas de las fotografias "no tienen padres que les cuiden", porque han muerto en la guerra, están prisioneros o les han abandonado. De todas las desgracias asociadas a las guerras que pueden padecerse en la infancia, la carencia o ruptura de la familia es la señalada como la más grave e incluso como la causa directa de otras situaciones desdichadas. Víctor, de 10 años, lo expresa así: "Lo peor es cuando un padre tiene varios hijos y al padre lo matan, esos niños ya no tienen futuro". La tristeza que algunos han visto en el rostro de los niños y las niñas de las fotografías no tiene su causa en la guerra sino en que "han perdido su familia". Sin familia todas las desagracias son posibles, el "abandono", la "falta de cariño", "que nadie te tape por las noches", etc.

Otro aspecto destacado en los relatos en relación con la familia es la «angustia" que reflejan los niños por no saber si sus padres están vivos, muertos, en prisión o enfermos. "Los niños piensan: ¿Y mis padres? ¿Dónde están? ¿Qué hacen?" (Álvaro, 8 años). Esta preocupación les lleva también a preguntarse: "¿Os imagináis lo que sería estar sin nadie, simplemente con gente que no conoces de nada?" (Soledad, 11 años). La vinculación con la familia es tan importante a estas edades que, a veces, puede justificar las acciones más inesperadas. "A las familias las tienen escondidas y no quieren sacarlas hasta que sus hijos maten a quienes les digan" (Verónica, 11 años). Y tampoco faltan quienes lamentan la pérdida en estas circunstancias de los placeres y comodidades que genera la vida familiar. Casilda de 12 años considera que en la guerra los niños "no tienen los padres que te dan dinero para chucherías, ni dinero para helados, ni dinero para juguetes".

Los niños manifiestan así mismo temor a que la guerra suponga la separación y perdida de los amigos: "La mayoría de sus amigos huérfanos se han muerto de hambre y de sed" (Sara, 11 años). A muchos les inquieta la posibilidad de que los 
amigos puedan convertirse, de repente, en enemigos: "Yo me sentiría muy mal porque tu mejor amigo podría matarte" (Verónica, 11 años). "Lo más seguro es que no tengan amigos porque les tengan miedo" (César, 11 años).

La guerra llena la vida de desamparo y soledad. "Lo que más destaca en esta imagen es la soledad de estos niños", dice Antonio, de 10 años. Y Montse, un año mayor, se mete en la piel de cualquiera de ellos y añade: "Una sensación de soledad sube por su espalda, hasta atraparle entre sus garras" (Montse, 11 años). Solos, sin familia y sin amigos, estos niños tienen que aprender desde muy pronto a valerse por sí mismos, "tendrán entre ocho y diez años, y por desgracia ya tienen que aprender a sobrevivir ellos solos", comenta Ángel, de 12 años.

El miedo que provoca la guerra paraliza la capacidad de expresar las emociones, incluso la de llorar por la pérdida de un padre, "para no meter demasiado jaleo" (Rocío, 10 años). Sólo la comprobación de que los seres queridos siguen vivos, proporciona un lugar para la alegría, y sólo la posibilidad de poder reunirse deja algún resquicio por el que experimentar "calor, amor y amistad" (Sara, 11 años). Otras veces, la rabia que se adivina en quienes sufren las consecuencias de la guerra es tan intensa que hace proyectar en ellos deseos de venganza:

Se escaparán del pueblo o ciudad de donde estén, y se irán por los montes. Pero lo que de verdad desean hacer es vengarse de los que mataron a sus familias y se irán por los campos para poder comer frutos o cualquier cosa que encuentren comestible. Y estarán unos años o el tiempo que haga falta para pedir dinero y reunir para poder comprarse una moto para los tres. Y cuando la tengan comprarán armas y matarán a los que mataron a sus familias y por lo tanto sus casas que es lo que les hicieron a ellos. Y trabajarán todo el tiempo que haga falta para comprarse un bazooka y derribarlas (Rodrigo, 11 años).

Para los niños, pensar en estas situaciones vitales y situar en ellas a otros de su edad, supone a menudo algo incomprensible, de lo que a veces escapan con la imaginación o protegiéndose tras imágenes estereotipadas. Por eso es explicable que quieran rescatar a los protagonistas de sus historias de este escenario, y que la vía más empleada sea la huida, aunque eso suponga tener que dejar atrás todo, "sus amigos, sus recuerdos, su infancia..." (Lucía, 12 años). Lo que tienen claro es que una persona que ha pasado por tal experiencia jamás podrá ya desprenderse de ella.

Cuando pasó la guerra se volvieron a juntar todos pero no se quitará nunca de sus mentes el sufrimiento de su familia y la muerte (Carolina, 11 años).

Quieren ser felices y que todo vuelva a ser como antes pero que nunca más les vuelva a ocurrir que haya otra guerra. Nunca se les va a olvidar lo que han sufrido si llegan a sobrevivir (Manuel, 11 años). 


\subsubsection{La influencia de los medios de comunicación}

Yo me he enterado de estas cosas por los medios de comunicación (Silvia, 11 años).

En los relatos de los niños se comprueba que la mayor parte de la información que tienen sobre las guerras proviene de los medios de comunicación, sobre todo de las imágenes que observan en la televisión. "Estas guerras que se producen y que salen en la tele me dan mucha pena" (Luz, 10 años). Detectamos que estas imágenes conforman una mirada que queda capturada por los aspectos emocionales de la situación: "Un niño murió en brazos de su padre y eso tiene que doler" (Noemí, 10 año) ${ }^{18}$. "Muchos niños intentan luchar contra ellos con tirachinas y no les hacen nada mientras los niños mueren" (Andrés, 9 años).

La influencia de los medios de comunicación se manifiesta en el uso que los niños hacen de algunos términos relacionados con la guerra o con situaciones de pobreza y sufrimiento que, como hemos visto, identifican con ella.

No se puede andar por la calle porque te puede estallar una mina antipersona (Samuel, 10 años).

La mayoría de estos países tienen por presidentes a personas que han dado golpes de Estado (Carmen, 10 años).

Son pobres, se esconden en un campo de refugiados (David, 9 años).

Lo está pasando muy mal, maltratados por la mafia en países subdesarrollados, una larga lista de países que se conocen como el Tercer Mundo, cuyos mandatarios, hacen con el dinero que les dan los países desarrollados, como los países de Europa y Estados Unidos, se lo gastan en provecho propio y en guerras, donde el que sale más perjudicado es su propio país, causando más deuda externa (Jesús, 12 años).

Otro dato significativo, muy posiblemente consecuencia de recibir la información a través de los medios de comunicación, es la identificación de todos los problemas sociales que generan sufrimiento con las situaciones de guerra. La amalgama de situaciones que se entrecruzan en los relatos infantiles, evoca la presentación "mezclada" de fenómenos diversos en secuencias rápidas de información, que suele ser habitual en los informativos de la televisión, los cuales "siempre están hablando de guerras" (Raquel, 11 años). Eso provoca que los problemas de extranjería y racismo, el conflicto árabe-israelí —Las niñas de esta fotografía normalmente vienen de Israel" (Leire, 10 años)—, los golpes de Estado, las catástrofes naturales, el paro, el SIDA, etc., formen parte de una misma situación, la guerra, expresión representativa del sufrimiento humano.

18. Esta frase recuerda la imagen de una noticia sobre el conflicto árabe-israelí aparecida reiteradamente en los medios de comunicación. 
No puedes pasar a una frontera, vale mucho dinero, a veces sólo puedes pasar a unas horas y si llegas tarde tienes que pasar al día siguiente. Tienes que dormir en el coche y te pueden matar mientras que duermes, a veces tienes que ir a pie y si a uno no le gusta tu cara iipun!! te matan (Alba, 10 años).

En países que no tienen suficiente trabajo como Marruecos, los niños se esconden entre las ruedas de los camiones para poder llegar a otros países donde haya trabajo y así poder comer, o bien lo hacen como una hazaña (Marta, 10 años).

Por último, aparece en los niños un cierto sentimiento ambivalente ante el papel social de los medios. Por una parte son receptivos a las campañas de concienciación que éstos hacen ante situaciones de extremo sufrimiento humano. "Los demás también hacemos lo posible haciendo campañas por los medios de comunicación, mandando comida, dinero... pero son muchos y no conseguimos hacer mucho" (Beatriz, 11 años). Pero, por otra, muestran también una cierta desconfianza hacia los medios, principalmente la televisión —el medio que más conocen y manejan- que, o no da toda la información o la da sesgada: "Los de la televisión nos mienten como quieren" (Víctor, 10 años).

\section{CONClusiones}

Comenzábamos este artículo peguntándonos qué puede hacer la educación moral ante las guerras y los conflictos, y sugeríamos que la respuesta que podamos dar a esa pregunta estará condicionada por nuestras aspiraciones y expectativas en torno a las posibilidades de este campo de investigación. Hace poco, una combinación de curiosidad histórica y azar, hizo que cayesen en nuestras manos las actas del Tercer Congreso Internacional de Educación Moral, organizado por el Instituto Jean Jacques Rousseau y celebrado en Ginebra en $1922^{19}$. En la presentación de Congreso, decía su presidente, Adolfo Ferrière:

La moral he dicho. Palabra muy poco a la moda, palabra descalificada a los ojos de muchos. Incluso entre los mejores espíritus del tiempo presente no está ya en olor de santidad [...].

Ciertos países de Europa muestran hoy bastante bien dónde se encuentra conducida la vida pública cuando cada uno predica, en la práctica, su moral - si se tiene realmente una, cuando no se tiene ninguna, que sea colectiva, y que ligue al individuo en nombre de un ideal一.

19. Según las informaciones que hemos podido recoger, aquel Congreso, desarrollado en la Universidad de Ginebra a finales de julio de 1922, contó con una participación de 500 personas, pocas si se comparan con las 1.800 que asistieron al Primer Congreso celebrado en Londres en 1908. La publicación de referencia corresponde al tomo de actas sobre La educación y la solidaridad. Existen varios volúmenes más con los trabajos presentados en el Congreso sobre El espiritu internacional y la enseñanza de la Historia e Informes y memorias, publicados en 1922 por DelaCHAUX y NiESTLE (Neuchâtel-Paris). 
¿Qué haremos nosotros para responder a esta objeción? Procuraremos probar la marcha marchando. Procuraremos discernir un fin que sea común a todos los hombres, y si lo logramos, probaremos que detrás de las morales existe la moral.

Una vez fijado este objetivo, las vías y los medios de tender a él se dibujarán por sí mismos (Ferrière, 1935, 6 y 7).

Al leer estas palabras, y recordar lo que ha sido la historia de la humanidad a lo largo de los ochenta años que han transcurrido desde entonces, surge enseguida la sensación de lo poco que aparentemente hemos avanzado. Sería, sin embargo, lamentable que esa sensación nos llevase a rebajar nuestro nivel de aspiraciones en cuanto a los logros a conseguir. Lo que procede es, más bien, permanecer, resistir y persistir en las mismas, y, por supuesto, cuestionar su sentido y, sobre todo, las vías que usamos para hacerlas realidad. Los educadores e investigadores de la educación nos sentimos desbordados cuando notamos que se nos ve como potenciales salvadores del mundo. No nos engañemos, ni nos dejemos engañar. Es una tarea imposible que nos impone, eso sí, el deber de ser, quizás un poco menos pretenciosos, como si el fin de la investigación pedagógica fuese acceder a la verdad absoluta, y sin duda bastante más prácticos. Esto es, al menos, lo que los tres autores de este trabajo hemos intentado llevar a cabo durante los últimos años con nuestros estudios y experiencias sobre determinados aspectos de la educación moral y cívica en la infancia. Si hemos colaborado aportando alguna idea al debate sobre educación moral, y si hemos animado a algunos de los veinte colegios con los que venimos trabajando a llevar a cabo algunas de nuestras propuestas, con eso ya nos damos por satisfechos. Toca, pues, ahora extraer, desde tal intención, las conclusiones e implicaciones pedagógicas de la investigación que aquí hemos presentado.

1. Los niños consideran que la guerra no tiene ningún sentido, ninguna utilidad. No encuentran razón alguna que la justifique. Piensan que si alguien quiere la guerra es porque no conoce ni imagina lo que se puede llegar a sufrir.

2. Los niños son capaces de ponerse en el lugar de las víctimas de la guerra, especialmente, cuando son también niños. Muestran una mayor empatía con las necesidades de sus iguales, imaginan su sufrimiento, saben determinar lo que les falta, y lo que esta situación no les permite hacer.

3. De todas las desgracias asociadas a los conflictos bélicos que pueden padecer los niños, la carencia o ruptura de la familia se identifica como la más grave. Temen también la pérdida de los amigos y, sobre todo, a que éstos se vean forzados a convertirse de repente en enemigos. La guerra llena la vida de desconfianza, sospecha y soledad, y obliga a la supervivencia por sí mismo.

4. Los niños piensan que la paz se puede lograr básicamente dialogando. Para ellos es necesario "discutir civilizadamente", encontrar soluciones que en ningún caso supongan sufrimiento. En sus relatos, la capacidad de hablar, de dialogar o de discutir tiene que llegar además a la voluntad de lograr acuerdos entre las partes afectadas. 
5. Los niños dan más valor a las condiciones necesarias para tener una vida digna que a la solución de los conflictos. La paz consiste más en lograr el bienestar de las personas que acabar con los motivos de la guerra.

6. En las elaboraciones narrativas de los niños, detectamos que la mayor parte de la información que tienen sobre la guerra proviene de los medios de comunicación, especialmente de las imágenes que observan en la televisión. Estas imágenes, junto con la ausencia de una información adecuada, conforman una mirada, en ocasiones, caótica y tremendista donde resulta más importante lo visual y emocionalmente significativo, comprensible para un niño, que unos datos explicativos que se presentan normalmente en formato para adultos.

7. Los niños identifican a menudo las situaciones de guerra con otros problemas sociales que generan sufrimiento. Pensamos que esta identificación puede deberse a la presentación habitual de todos estos fenómenos juntos en unos mismos paquetes de información, en los que predomina la inmediatez del mensaje y la volatilidad de la información, tal como suele hacerse en los informativos de la televisión.

8. Los niños se muestran receptivos a las campañas de concienciación que los medios de comunicación hacen ante situaciones de carencia. Piensan que un modo de paliar las consecuencias negativas de los conflictos bélicos consiste en colaborar con el envío de alimentos, donaciones, etc. El sufrimiento de los otros despierta en ellos una actitud de compasión y de solidaridad que resulta indispensable para poder realizar una auténtica educación para la paz.

9. La educación para la paz requiere la promoción de sentimientos y actitudes de solidaridad y empatía hacia los otros. Así mismo, requiere un conocimiento, adaptado a las capacidades de los niños, sobre las causas que ayudan a entender los conflictos humanos. Ambas dimensiones son necesarias para aprender a leer, analizar y responder las informaciones e imágenes que proporcionan los medios de información. Sólo si se trabajan ambas se podrá conseguir una educación para la paz que evite tanto el voluntarismo sensiblero como el racionalismo insensible. Las propuestas de educación moral para la paz, suelen insistir en la primera dimensión. Los datos de nuestra investigación revelan la necesidad de trabajar también la segunda.

10. Los resultados obtenidos deberían ampliarse en futuras investigaciones recurriendo a imágenes diferentes que nos proporcionasen otras categorías vinculadas a la vida cotidiana de los niños. 


\section{BIBLIOGRAFÍA}

AsAmblea General de las NACIONES Unidas (2000) Decenio Internacional de una cultura de paz y no violencia para los niños del mundo. Informe del Secretario General (Documento $\left.\mathrm{N}^{\circ} \mathrm{A} / 55 / 377\right)$.

BÁrCENA, F. (1997) El oficio de la ciudadanía. Introducción a la educación política. Barcelona, Paidós.

- (2001) La esfinge muda. El aprendizaje del dolor después de Auschwitz. Barcelona, Anthropos.

BÁrCENA, F.; GIL, F. y Jover, G. (1995) La socialización como forma de educación moral. Una propuesta en el contexto de la reforma educativa, Pedagogía Social. Revista Interuniversitaria, 11, 183-202.

BARRIO, J. M. ${ }^{a}$ (2002) La educación para la paz como tarea cultural, en Educación, ética y ciudadanía. Actas del IV Congreso Internacional de Filosofía de la Educación. Madrid, UNED, 37-54.

BARrio, J. M. ${ }^{2}$ (2003) Cerco a la ciudad. Una filosofía de la educación cívica. Madrid, Rialp.

BROCK-UTNE, B. (1994) The distinction between education about peace and development and value centred education intended to promote them, en RAY, D. et al., Education for buman rights. Paris, Unesco/International Bureau of Education, 55-81.

ESCÁMEZ, J. (1983) Educación y normatividad, en AA.VV., Teoría de la Educación I (El problema de la educación). Murcia, Ediciones Límites, 62-77.

EsCÁmEZ, J. (2003) Los valores y la educación en España, en SEMINARIo INTERUNIVERSTARIO de TeOría de la Educación. Teoría de la Educación, ayer y boy. Murcia, Selegráfica, 205-237.

FERRIÈRE, A. (1935) Prefacio, en La educación y la solidaridad. Trabajos presentados en el Tercer Congreso Internacional de Educación Moral. Madrid, Espasa-Calpe, 5-9.

GiL, F. y Jover, G. (1998) La experiencia de los derechos en contextos de aprendizaje escolar: una investigación a través de las Nuevas Tecnologías, Revista Española de Pedagogia, no 211, 561-586.

- (2000) Las tendencias narrativas en pedagogía y la aproximación biográfica al mundo infantil, Enrabonar, $n^{\circ} 31,107-122$.

- (2003) La contribución de la educación ética y política en la formación del ciudadano, Revista de Educación, número extraordinario de 2003, 109-129.

GIL, F.; JoVER, G. y REYERO, D. (2001) La enseñanza de los derechos humanos. 30 preguntas, 29 respuestas y 76 actividades. Barcelona, Paidós.

Giroux, H. A. (1994) Disturbing Pleasures. Learning Popular Culture. New York, Routledge.

IBÁÑEZ-Martín. J. A. (1983) La educación moral en una sociedad pluralista, La Escuela en Acción, enero, 17-19.

- (2000) Los profesores como constructores de la paz, Revista Española de Pedagogía, $\mathrm{n}^{\circ} 216,235-251$.

- (2002) La universidad ante el reto de la educación para la ciudadanía, en Educación, ética y ciudadania. Actas del $N$ Congreso Internacional de Filosofía de la Educación. Madrid, UNED, 17-36.

JOVER, G. y REYERO, D. (2000) Images of the other in childhood: researching the limits of cultural diversity in education from the standpoint of new anthropological methodologies, Encounters on Education/Encuentros sobre Educación/Rencontres sur l'Éducation, 1, 127-152. 
FERNANDO GIL CANTERO, GONZALO JOVER OLMEDA Y DAVID REYERO GARCÍA

MarTín, X. (1994) Aportaciones y límites de los paradigmas cognitivo y dialógico en educación moral, Teoria de la Educación. Revista Interuniversitaria, vI, 127-147.

ORTEGA, P. (1986) La investigación en la formación de actitudes: problemas metodológicos y conceptuales, Teoria de la Educación. Revista Interuniversitaria, I, 111-125.

ORTEGA, P. y Mínguez, R. (2001) Los valores en la educación. Barcelona, Ariel.

Puig Rovira, J. M. ${ }^{a}$ (1986) Teoría de la educación. Una aproximación sistémico-cibernética. Barcelona, PPU.

SACRISTÁn, D. (1988) La importancia del esfuerzo en el proceso educativo, en ALVIRA, R. et al., Dimensiones de la voluntad. Madrid, Dossat, 115-141.

UNIVERSIDAD COMPLUTENSE DE MADRID (1995) Producción investigadora en los diversos ámbitos científicos del Departamento de Teoría e Historia de la Educación. Valencia, Imprenta Nácher.

UnIVERSIDAD COMPLUTENSE DE MADRID (2001) Publicaciones cientificicas del Departamento de Teoria e Historia de la Educación (1990-2000). Valencia, Imprenta Nácher. 